Marquette University

e-Publications@Marquette

Biomedical Engineering Faculty Research and

Publications

Biomedical Engineering, Department of

$1-16-2008$

\title{
Mechanical Behavior and Failure Analysis of Prosthetic Retaining Screws after Long-term Use in vivo. Part 4: Failure Analysis of 10 Fractured Retaining Screws Retrieved from Three Patients
}

\author{
Youssef S. Al Jabbari \\ King Saud University \\ Raymond Fournelle \\ Marquette University, raymond.fournelle@marquette.edu \\ Gerald J. Ziebert \\ Marquette University \\ Jeffrey M. Toth \\ Marquette University, jeffrey.toth@marquette.edu \\ Anthony lacopino \\ University of Manitoba
}

Follow this and additional works at: https://epublications.marquette.edu/bioengin_fac

Part of the Biomedical Engineering and Bioengineering Commons

\section{Recommended Citation}

Al Jabbari, Youssef S.; Fournelle, Raymond; Ziebert, Gerald J.; Toth, Jeffrey M.; and lacopino, Anthony, "Mechanical Behavior and Failure Analysis of Prosthetic Retaining Screws after Long-term Use in vivo. Part 4: Failure Analysis of 10 Fractured Retaining Screws Retrieved from Three Patients" (2008).

Biomedical Engineering Faculty Research and Publications. 553.

https://epublications.marquette.edu/bioengin_fac/553 
Marquette University

\section{e-Publications@Marquette}

\section{Biomedical Engineering Faculty Research and Publications/College of Engineering}

This paper is NOT THE PUBLISHED VERSION; but the author's final, peer-reviewed manuscript.

The published version may be accessed by following the link in the citation below.

Journal of Prosthodontics, Vol. 17, No. 3 (April, 2008): 201-210. DOl. This article is (C) Wiley and permission has been granted for this version to appear in e-Publications@Marquette. Wiley does not grant permission for this article to be further copied/distributed or hosted elsewhere without the express permission from Wiley.

\section{Contents}

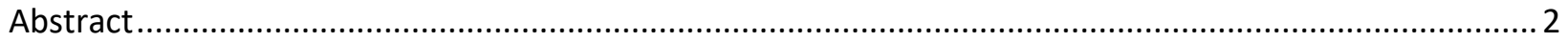

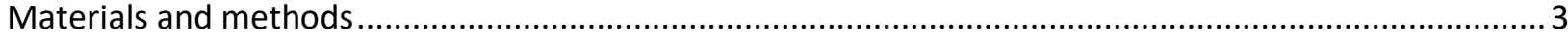

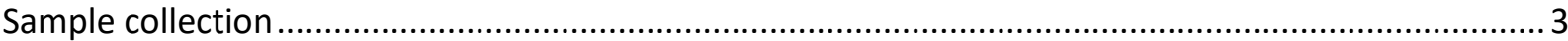

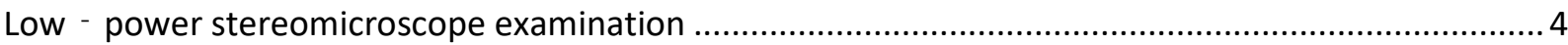

Scanning electron microscopy (SEM) examination....................................................................... 4

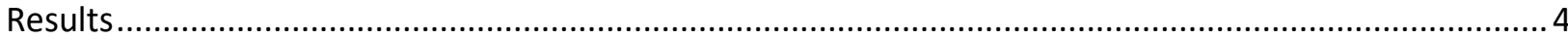

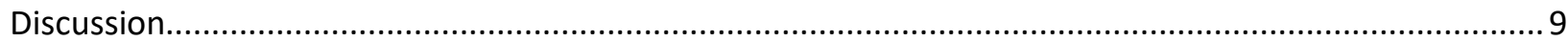

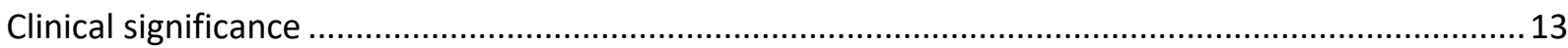

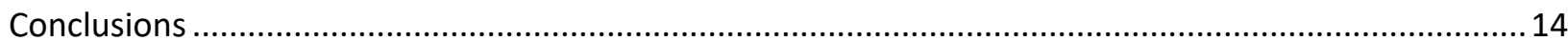

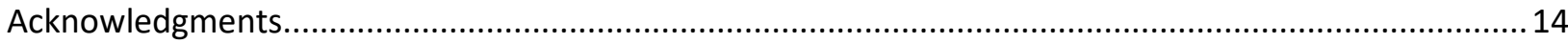

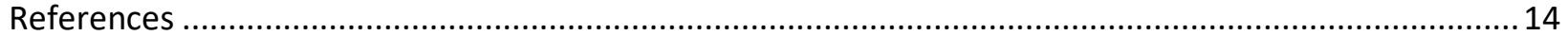

\section{Mechanical Behavior and Failure Analysis of Prosthetic Retaining Screws after Long-}




\title{
term Use in vivo. Part 4: Failure Analysis of 10 Fractured Retaining Screws Retrieved from Three Patients
}

\author{
Youssef S. Al Jabbari \\ Department of Prosthodontic Dental Sciences, King Saud University College of Dentistry, \\ Riyadh, Saudi Arabia
}

Raymond Fournelle

Department of Mechanical and Industrial Engineering, Marquette University, Milwaukee, WI Gerald Ziebert

Division of Prosthodontics, Marquette University School of Dentistry, Milwaukee, WI Jeffrey Toth

Division of Dental Biomaterials, Marquette University School of Dentistry, Milwaukee, WI Anthony M. lacopino

Restorative Dentistry, University of Manitoba Faculty of Dentistry, Winnipeg, Manitoba, Canada

\section{Abstract}

Purpose: The aim of this study was to perform a failure analysis on fractured prosthetic retaining screws after long-term use in vivo. Additionally, the study addresses the commonly asked question regarding whether complex repeated functional occlusal forces initiate fatigue-type cracks in prosthetic retaining screws.

Materials and Methods: Ten fractured prosthetic retaining screws retrieved from three patients treated with fixed detachable hybrid prostheses were subjected to a failure analysis. In patients 1 and 2, the middle three retaining screws of the prostheses were found fractured at retrieval time after they had been in service for 20 and 19 months, respectively. In patient 3, the middle three and one of the posterior retaining screws were found to be fractured at retrieval after they had been in service for 18 months. Low power stereomicroscopy and high-power scanning electron microscopy (SEM) were performed to analyze the fractured surfaces of the retaining screws examining fatigue cracks in greater detail.

Results: Typical fatigue failure characterized by ratchet mark formation was revealed by light microscopy and SEM for all examined screws. Using low magnification light microscopy, ratchet marks were visible on the fracture surfaces of only two screws. SEM examination revealed all three classical stages of fatigue failure, and it was possible to see the ratchet marks on the fracture surfaces of all specimens, indicating a fatigue zone. The final catastrophic overload fracture appeared fibrous, indicating ductile fracture. The final overload ductile fracture surfaces showed equiaxed dimples, 
suggesting tensile overload in all examined screws except in two specimens that showed an elongated dimple pattern indicating shear/tearing overload forces.

Conclusions: Fracture of prosthetic retaining screws in hybrid prostheses occurs mainly through a typical fatigue mode involving mostly the middle anterior three screws. Fatigue cracks can grow in more than one prosthetic retaining screw, leading to fracture before the patient or clinician determines that any problem exists.

Although the use of implant-retained and -supported fixed detachable hybrid prostheses has become a very successful treatment for totally edentulous patients, one of the commonly encountered complications is clamped joint instability as a result of screw loosening and/or fracture.1-3 Because prosthetic retaining screws are designed to be the weakest-link component in fixed detachable hybrid prosthesis and are used as a "break-safe" mechanism, the occurrence of screw loosening and/or fracture is expected to occur more frequently than for abutment screws.4, 5 If patients and/or clinicians fail to detect loose retaining screws early on, inevitable screw fracture will occur, leading to more complicated, time consuming, and expensive repairs.

A 31\% occurrence of retaining screw loosening in edentulous patients has been reported 2 weeks after insertion. 6 Other studies have reported: (1) 5\% loosening of all retaining screws placed in 91 patients; 7 (2) $9 \%$ implant screw loosening in 56 complete and partially edentulous patients treated with implantretained and -supported prostheses with screw failure in $25 \%$ of the patients; 8 and (3) 53 prosthetic retaining screw fractures as complications of implant treatment. 4 A summary of various studies indicates a 1-9\% occurrence of retaining screw fracture.9 Implant screw loosening and/or loss of osseointegration (mechanical and/or biological failures) have been attributed to unfavorable biomechanical factors, such as occlusal overload and/or poor stress distribution.2, 3, 10 Two studies regarding implant screw loosening and fracture11, 12 suggested the following to minimize such problems: (1) occlusal forces should be directed to the long axis of the implant by placing the implant in a favorable position in relation to the opposing occlusion; (2) cantilevers should be as short as possible in fixed detachable hybrid prostheses; (3) application of recommended preload and use of gold screws; and (4) establishing a proper and accurate occlusion.

To date, only in vitro studies have attempted to investigate the effect of functional cyclic loading on implant system components, or to explain the mechanism of implant screw loosening and characterize the mode of failure.13-17 The aim of this study was to perform a failure analysis on fractured prosthetic retaining screws after long-term use in vivo. Additionally, the study addressed the commonly asked question regarding whether complex repeated functional occlusal forces initiate fatigue-type cracks in prosthetic retaining screws.

\section{Materials and methods}

\section{Sample collection}

Ten fractured prosthetic retaining screws retrieved from three patients treated with fixed detachable hybrid prostheses were subjected to failure analysis. All three patients came to the dental office complaining of loose prostheses. The fractured retaining screws were in Groups 16, 17, and 20 in Table 1 of Part 1 of this series. In patients 1 (Group 16) and 2 (Group 17), the middle three retaining screws of 
the prostheses were found to be fractured at retrieval after they had been in service for 20 and 19 months, respectively. In patient 3 (Group 20), the middle three and one of the posterior retaining screws were found to be fractured at retrieval after they had been in service for 18 months (refer to Table 1 in Part 1 of this series for more detail regarding group classification system, screw manufacturer, and inservice history). All the retaining screws were made by Sterngold (SG; Sterngold ImplaMed, Attleboro, MA) and used with the Nobel Biocare (Göteborg, Sweden) implant system. Screws were carefully handled during all stages of analysis and testing, using only plastic tweezers. Prior to testing, each screw was ultrasonically cleaned. Screws were placed individually in a glass beaker containing water/Alconox detergent powder (Alconox Inc., White Plains, NY) and ultrasonically cleaned for 10 minutes. Each screw was placed in a different glass beaker containing methanol and ultrasonically cleaned for an additional 5 minutes.

\section{Low-power stereomicroscope examination}

Low-power stereomicroscopy was used as the first-step for performing failure analysis (Meiji MZS-TR Model, Meiji Techno Co., Ltd., Saitama, Japan). A fiber optic light source was used for illumination (Lumina-I, Chiu Technical Corp., Kings Park, NY), and white paper was used to provide a neutral background. Prosthetic screws were examined and photographed within a white paper barrel that distributed the light more evenly and prevented glare. Photography was performed using an Image Analysis System comprised of a Sony CCD digital camera (DXC 151A, Sony, Tokyo, Japan) coupled to a computer with photo analysis software (Image Pro Plus 4.0 software, Media Cybernetics Inc., Bethesda, $\mathrm{MD})$.

\section{Scanning electron microscopy (SEM) examination}

SEM was used to analyze the fractured surfaces of the retaining screws in more detail. A JEOL JSM 35 scanning electron microscope (JEOL USA Inc., Peabody, MA) was operated according to manufacturing instructions at $25 \mathrm{Kev}$, using secondary electron imaging.

\section{Results}

Light and scanning electron microscopy revealed typical fatigue failure on the fracture surfaces of the retrieved implant prosthetic retaining screws in Groups 16, 17, and 20. All of the middle three retaining screws from each group and one of the two posterior screws in Group 20 were fractured with moderate to severe thread wear. The remaining two posterior screws in each group were intact with mild thread wear. The fatigue fracture occurred in the shank area of all prosthetic screws, with the exception of the posterior screw in Group 20, for which fracture occurred in the threaded area (ig 1).

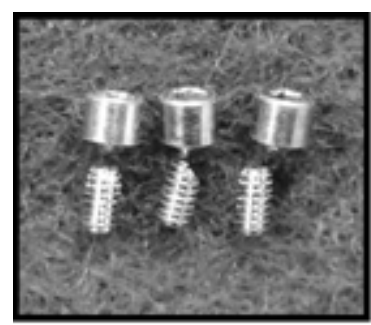

A

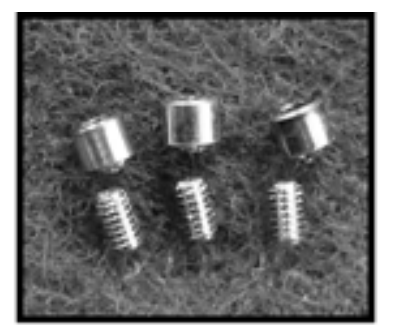

B

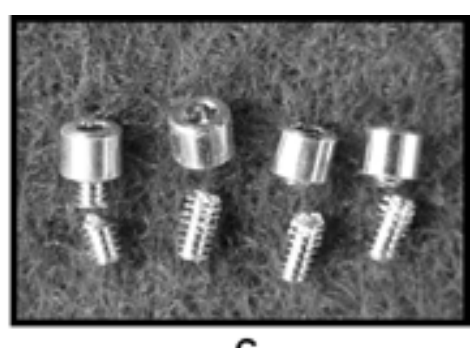

C

Figure 1 Fractured prosthetic retaining screws. Representative samples from groups $16(A), 17(B)$, and 20 (C). Note that fracture occurred in the shank area for all screws except for $20 \mathrm{~B}_{1}$, for which fracture occurrence was in the threaded segment of the screw. 
Low-magnification light microscopy of the fracture surfaces of the prosthetic retaining screws suggested that fatigue failure was the primary mode of fracture (ratchet marks were observed). Ratchet marks were visible on the fracture surfaces of specimens $16 \mathrm{~A}_{1}$ and $17 \mathrm{~A}_{2}$ but were not visible on the fracture surfaces of other specimens (Fig 2). Additionally, light microscope examination revealed yellow fibrous (rutted) areas on the fracture surfaces representing the areas of final fracture when the fatigue crack reached its critical length and the cross-section area was reduced to the point where it could not carry the load.

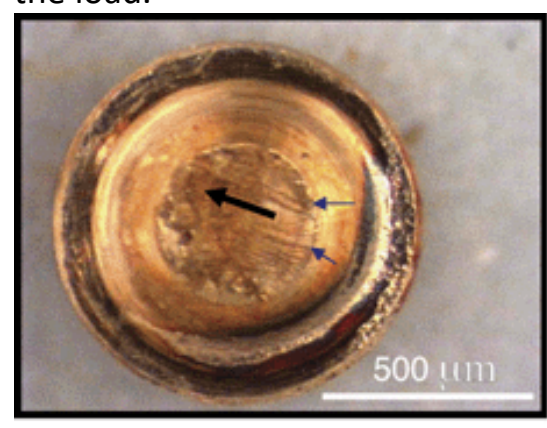

A

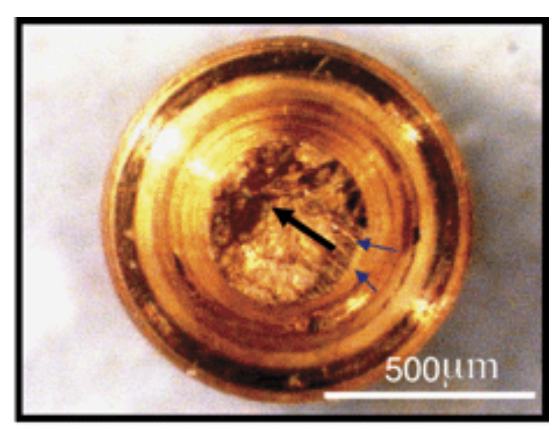

B

Figure 2 Light microscope photograph of fatigue fracture surfaces of prosthetic retaining screws. (A) 16A1(B) 17A2. Note the ratchet marks evenly dispersed along the periphery (blue arrows). Black arrows indicate fatigue crack propagation direction.

SEM revealed more detail of the fatigue fracture surfaces. At low magnification ( $\times 65)$, it was possible to see the ratchet marks on the fracture surfaces of all specimens. They were dispersed evenly along the periphery of the fatigue zone. The final catastrophic overload fracture appeared fibrous, indicating ductile fracture. The fatigue fracture surfaces of specimens $16 A_{1}, 17 A_{2}$, and $20 A_{1}$ are the best representative examples of the fatigue fracture surfaces for Groups 16, 17, and 20. Figure 3A is a lowmagnification $(\times 65)$ SEM fractograph of the fatigue fracture surface of specimen $16 A_{1}$. It illustrates a typical fatigue fracture surface characterized by ratchet marks parallel to the direction of crack propagation. The fibrous gray area indicates the final overload ductile fracture. The distinction between the area of fatigue crack propagation and that of final overload ductile fracture was very visible, whereas the distinction between the two areas was not clear for the fatigue fracture surfaces of specimens $16 \mathrm{~A}_{2}$ and $16 \mathrm{~A}_{3}$ at low magnification (x65). It was possible, however, to distinguish between the two areas under higher magnification, at which the fatigue crack propagation area was characterized by fatigue striations, and the final overload ductile fracture area was characterized by dimple formation. As can be seen in Figure $3 \mathrm{~A}$, the fatigue crack covered approximately $40 \%$ of the fracture surface as indicated by the outline in yellow, until final rapid overload fractured occurred (red area). For specimens $16 A_{1}, 16 A_{2}$, and $16 A_{3}$, the ratio of fatigue crack propagation area to the final overload ductile fracture area was 0.4:0.6, 0.6:0.4, and 0.8:0.2, respectively ( $\underline{\text { Fig } 3}$ ). 


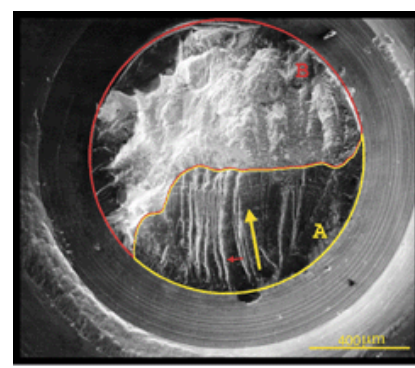

A

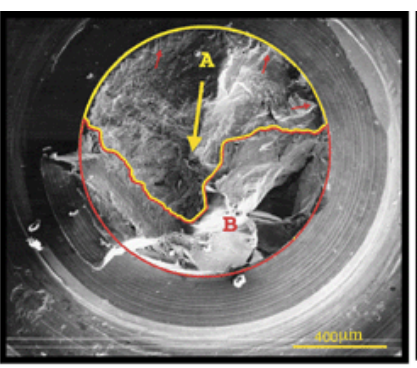

B

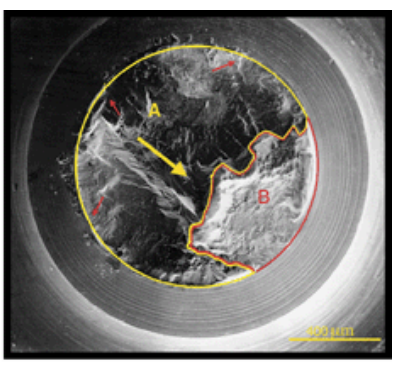

C

Figure 3 Scanning electron microscopy (SEM) fractograph of specimens 16A1 (A),16A2 (B), and 16A3 (C). In (A) the fracture surface shows well - formed and distinct ratchet marks (red arrow) parallel to crack propagation (yellow arrow). In both (B) and (C) fatigue fracture surfaces show fine ratchet marks on the periphery (red arrows). Region A is fatigue crack, and region $B$ is final catastrophic overload fracture. The yellow arrow indicates the fatigue crack propagation direction.

Figure $4 \mathrm{~A}$ is a high-magnification $(\times 1500)$ SEM fractograph of one of the fatigue crack initiation sites for specimen $16 A_{1}$. It illustrates typical fatigue striations, which are normally associated with fatigue cracks in ductile material. Figure 4B is another high-magnification $(\times 500)$ SEM fractograph for specimen $16 A_{1}$. It demonstrates the transition of the fatigue crack from the crack propagation stage (stage II) to the final overload fracture stage (stage III). Stage II shows parallel ratchet marks along the crack propagation direction and very fine fatigue striations perpendicular to the crack direction. Stage III shows dimple formation, which might be a result of a single occlusal (bite) overload force.

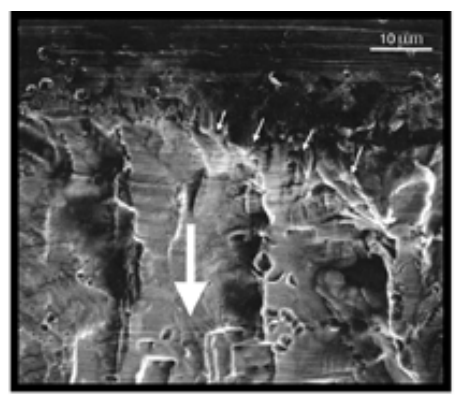

A

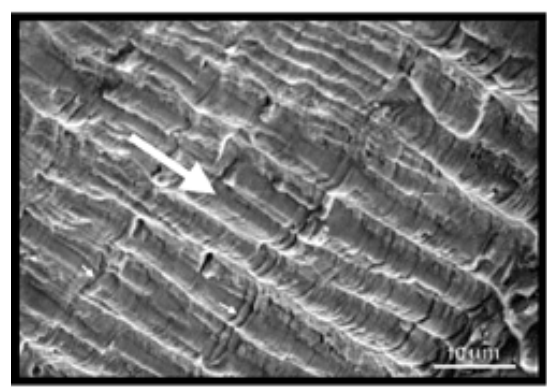

C

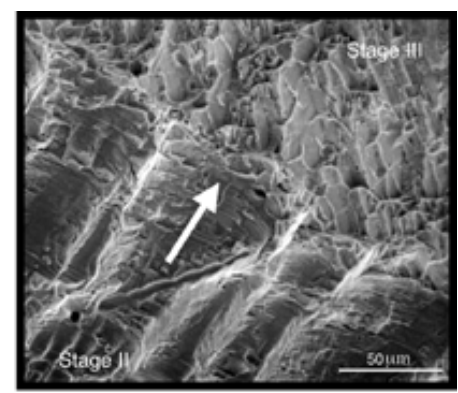

B

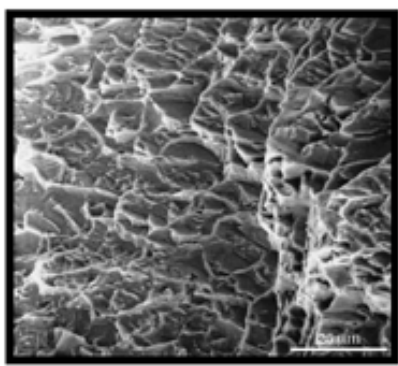

D

Figure 4 SEM fractograph of specimen 16A1. (A) Shows the origin of fatigue fracture as indicated by small arrows. Note fine striations within the fatigue crack propagation region. (B) Shows the transition from fatigue crack propagation stage (stage II) to final overload fracture (stage III). Stage II is characterized by ratchet marks and striations, and stage III is characterized by equiaxed dimples. Bold arrows indicate the crack propagation direction. (C) Shows the local variation of the orientation of the fatigue striations due to 
microstructural features. Note the variation of the striation banding or spacing (small arrows) due to varying stress magnitudes. Large, bold arrow in (A), (B), and (C) indicates crack propagation direction. (D) Shows equiaxed dimples indicating the final ductile overload fracture (stage III).

Figure $4 \mathrm{C}$ is a high - magnification $(\times 1500)$ SEM fractograph of stage II for specimen $16 \mathrm{~A} 1$. It shows two common, interesting features of fatigue striations. First, there is local variation of the orientation of the fatigue striations due to differing microstructural features through which the crack was advancing. Second, there is variation of the striation spacing due to the differing magnitudes of occlusal cyclic loading. Careful examination of the striation spacing in Figure $4 \mathrm{C}$ may suggest occlusal loading magnitude. The wider the striation, the higher the magnitude of occlusal forces. Figure 4D is a high magnification $(\times 1000)$ SEM fractograph of stage III for specimen 16A1. It shows equiaxed dimples, which are usually caused by tensile overload.

Figure $5 B$ is a low - magnification $(\times 65)$ SEM fractograph of the fracture surface of specimen $17 A 2$. It shows fatigue features similar to those seen in Figure 3A. The ratchet marks, however, are visible only at the periphery of the fracture surface and start to disappear as the fatigue crack propagates.

Additionally, the distinction between the area of the fatigue crack growth and that of the final overload ductile fracture was not as clear as it was in Figure 3A. Distinction between the two areas was possible under higher magnification. For specimens $17 \mathrm{~A} 1,17 \mathrm{~A} 2$, and $17 \mathrm{~A} 3$ the ratios of the fatigue crack propagation areas to the final overload ductile fracture areas were 0.8:0.2, 0.85:0.15, and 0.7:0.3, respectively (Fig 5).



A

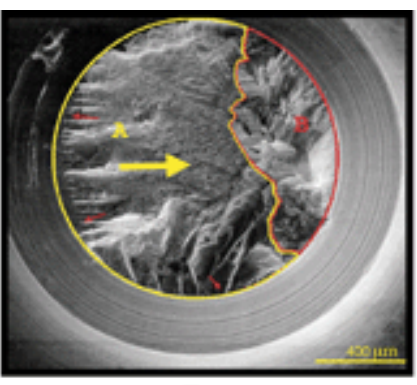

B

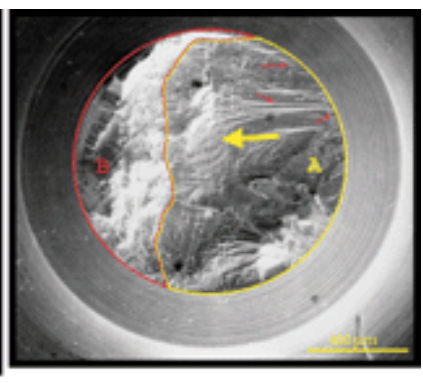

C

Figure 5 SEM fractograph of specimens 17A1 (A), 17A2 (B), 17A3 (C). In (A) and (B) fatigue fracture surfaces show fine ratchet marks on the periphery (red arrows), while in (C) fatigue fracture surface shows fine ratchet marks on the periphery with a very distinct band of ratchet marks in the middle (red arrows). Region $A$ is fatigue crack propagation (stage II), and region B is final catastrophic overload fracture (stage III).Yellow arrow indicates crack propagation direction.

Figures $6 A$ and $B$ are high-magnification $(\times 2000$ and $\times 600)$ SEM fractographs for specimen $17 A_{2}$. Figure $\underline{6 A}$ shows typical fatigue striations similar to those seen in Figures $4 A$ and $C$, whereas Figure $6 \mathrm{~B}$ shows an equiaxed dimple pattern of final overload ductile fracture similar to those found on the fracture surface of specimen $16 A_{1}$ in Figures $4 B$ and $D$. An elongated dimple pattern was observed on the final catastrophic overload fracture surfaces of $16 A_{2}$ and $17 A_{1}$, indicating shear or tearing overload forces (Figs 6C, D). 


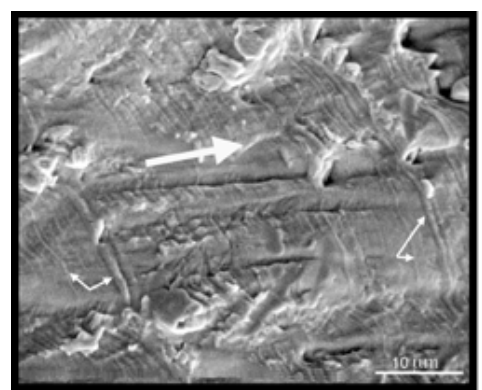

A

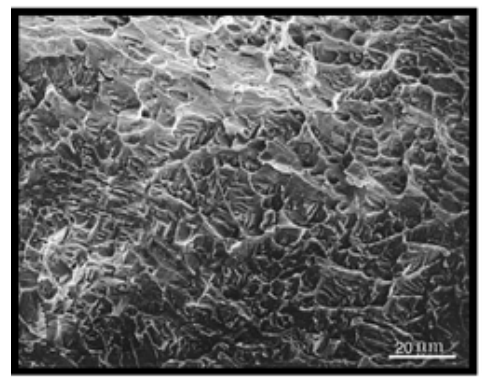

C

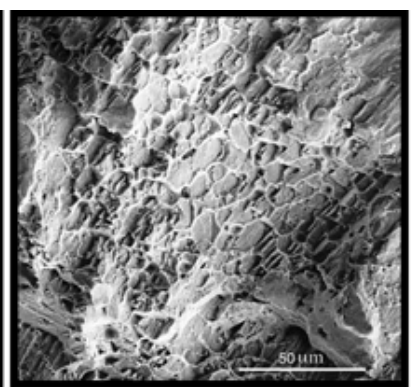

B

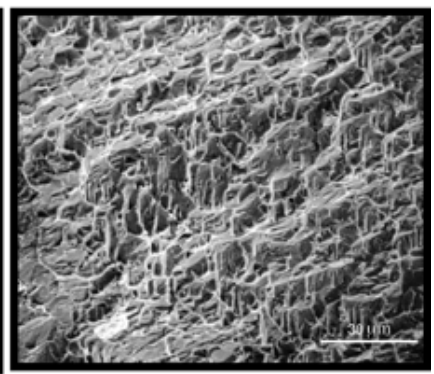

D

Figure 6 SEM fractograph for specimen 17A2. (A) Shows the fatigue crack propagation (stage II). Note local variation of the striation spacing (small arrows) due to repeated stress cycles. Large, bold arrow indicates crack propagation direction. (B) Demonstrates the final overload fracture (stage III), which was characterized by equiaxed dimples formation. (C) \& (D) demonstrate elongated dimple pattern formation of the final overload fracture (stage III) for specimens $16 \mathrm{~A} 2$ and 17A1, respectively.

Figure 7 shows low-magnification ( $\times 65$ ) SEM fractographs for specimens $20 \mathrm{~A}_{1}, 20 \mathrm{~A}_{2}, 20 \mathrm{~A}_{3}$, and $20 \mathrm{~B}_{1}$. They show features similar to those seen in Figure 3. For specimens $20 \mathrm{~A}_{1}, 20 \mathrm{~A}_{2}, 20 \mathrm{~A}_{3}$, and $20 \mathrm{~B}_{1}$ the ratios of the fatigue crack propagation area to the final overload ductile fracture areas were $0.75: 0.25$, 0.4:0.6, 0.55:0.45, and 0.5:0.5, respectively. Figure $8 \mathrm{~A}$ is a high-magnification $(\times 1000)$ SEM fractograph of the fatigue crack initiation sites for specimen $20 \mathrm{~A}_{1}$. It shows the first two stages (stage I and II) of fatigue crack initiation and propagation. Stage I extends inward from the surface (usually along a slip band about $45^{\circ}$ to the tensile stress axis) 18 with no associated striations. It was the only specimen for which stage I was observed on the fracture surface. Stage II, on the other hand, shows the change of orientation of crack propagation as it becomes perpendicular to the long axis of the implant screw and the tensile loads. Stage II contains typical fatigue striations similar to those seen in Figures $4 \mathrm{~A}, 4 \mathrm{C}$, and $\underline{6 \mathrm{~A}}$. 


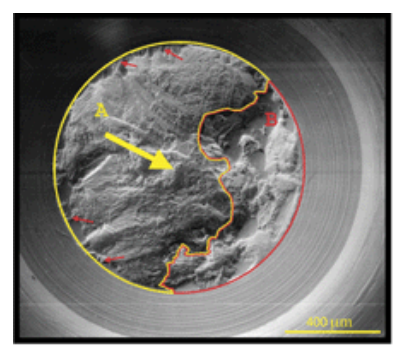

A

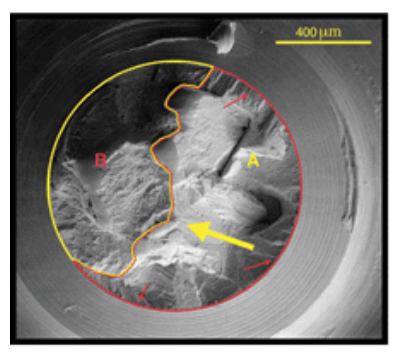

C
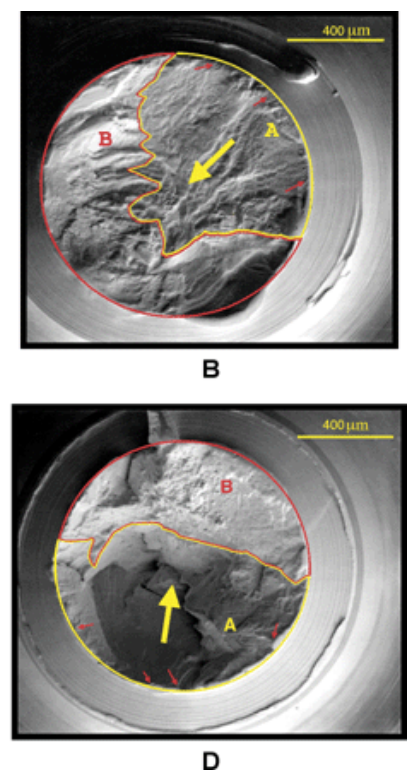

Figure 7 SEM fractograph of specimens 20A1, 20A2, 20A3, and 20A4 are shown in (A), (B), (C), and (D), respectively. Fatigue fracture surfaces show fine ratchet marks on the periphery (red arrows). Region $\mathbf{A}$ is fatigue crack propagation (stage II) and region B is final catastrophic overload fracture (stage III). Yellow arrow indicates crack propagation direction.

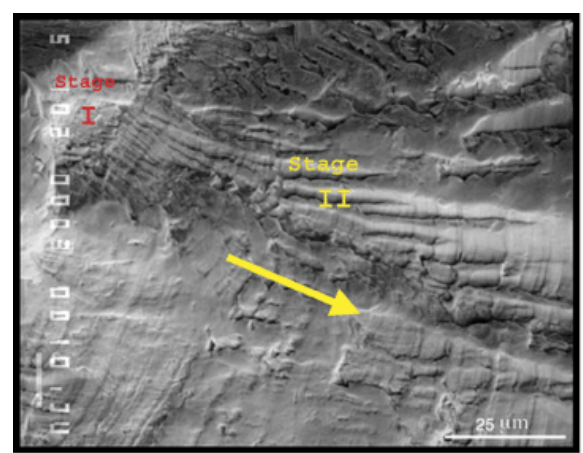

A

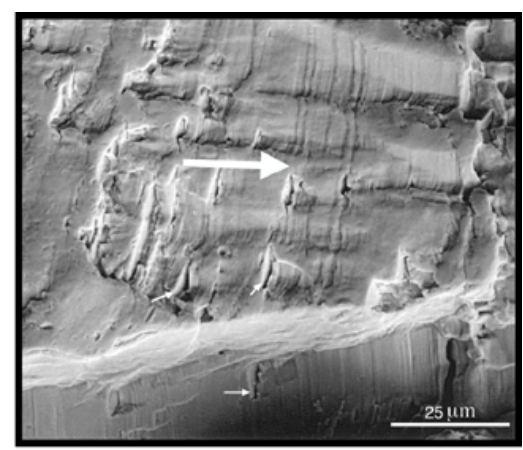

B

Figure 8 SEM fractograph of specimen 20A1. (A) shows the transition from stage I to stage II at the periphery of the fracture surfaces (yellow arrow indicates crack propagation direction). (B) shows stage II with secondary cracks (small arrows) associated with striations perpendicular to the fatigue crack propagation direction (large, bold arrow).

Figure $8 \mathrm{~B}$ is another high-magnification $(\times 1000)$ SEM fractograph of fatigue crack propagation from a different location for specimen $20 \mathrm{~A}_{1}$. It illustrates typical fatigue striations with secondary crack formation.

\section{Discussion}

Metal fatigue is caused by repeated loading at stress levels above the endurance limit of a susceptible material.18 In this study, it was possible to see features of fatigue failure at both the macroscopic and microscopic level for all fracture surfaces of prosthetic retaining screws examined. Macroscopically, the 
fatigue fracture surfaces exhibited two distinct regions, a fatigue crack propagation region and a final overload ductile region. The ratio of the areas of the two regions to each other provided a better understanding of the fatigue with regard to the number of occlusal load cycles and stress level. Normally, if the stress level from occlusal (biting) forces is relatively low, it takes many cycles for the fatigue crack to propagate to a location where the remaining material would fracture catastrophically on the next (and final) occlusal load application ( $\underline{\mathrm{Fig}}$ ). 18 Thus, for lower loads, the relative amount of the fracture surface covered by fatigue crack propagation will be larger than the surface covered by final occlusal overload fracture. On the other hand, if the stress level is high, then the fatigue crack will not propagate far before final fracture occurs.18 Accordingly, in this study, failed screws with larger fatigue crack propagation areas (probably $70 \%$ or more) are most likely the ones that initiated fatigue cracking and failure. Therefore, the observed stage I propagation in Figure 8A of this study might indicate that the retaining screw was subjected to a very low stress level and was the first screw that initiated fatigue cracking and failure. Many factors can initiate or produce stage I propagation such as: (1) surface finishing micro-cracks; (2) scratches and/or deformations due to improper handling; (3) manufacturer defects; and (4) corrosion.18, 19 In this study, corrosion was not considered to be a major causative factor of fatigue failure, because the prosthetic screws were made from noble materials as determined by energy dispersive X-ray analysis in Part 2 of this series. The noble metals are resistant to corrosion. $\underline{20}$ Retaining prosthetic screws, however, are more sensitive to the effect of surface finish and scratches/deformation due to improper handling. It was possible to see both manufacturer machining irregularities and surface damage on one of the non-fractured screws $\left(15 \mathrm{~B}_{1} ; \underline{\text { Fig } 10}\right)$.

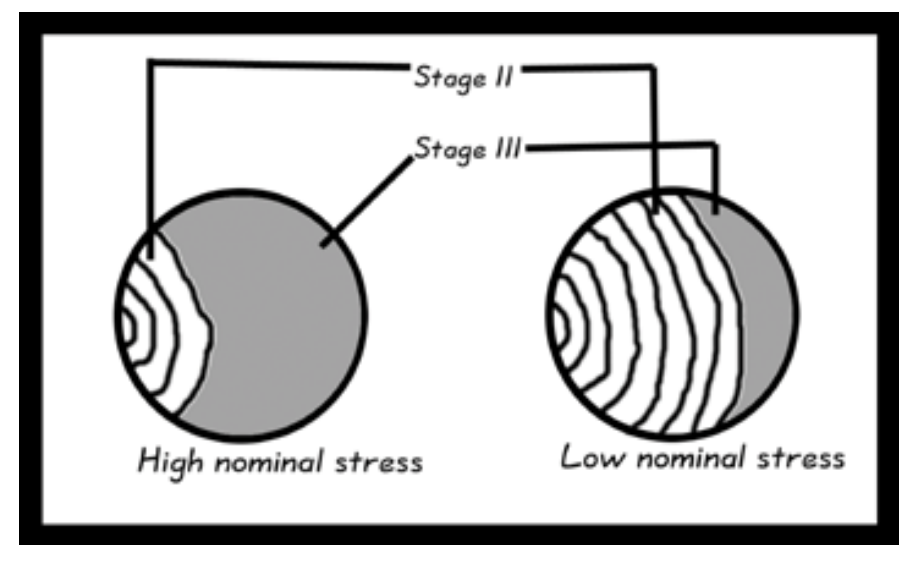

Figure 9 Schematic illustration of a fatigue fracture surface and the effect of loading conditions and stress level on the relative area covered by the fatigue crack. 


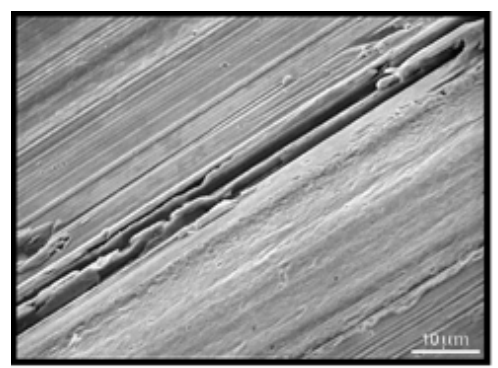

A

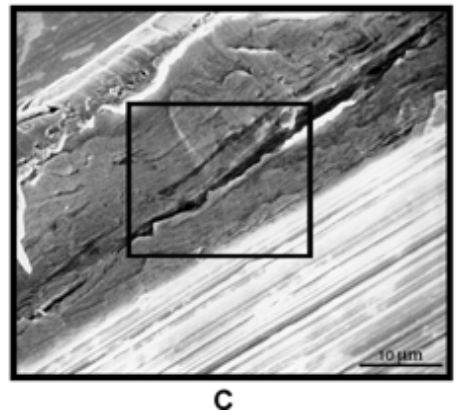

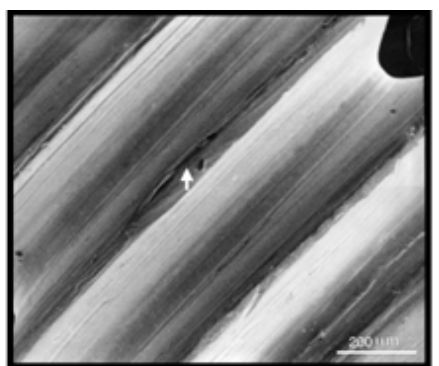

B

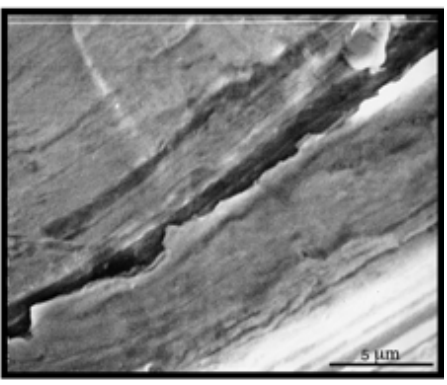

D

Figure 10 SEM micrograph of the15B1 prosthetic screw. Variability of machining roughness and irregularities in the head area are demonstrated in (A). (B) Localized damage to the crest of a thread (white arrow). (C) High magnification view of the area in (B) at $\times 2000$ showing severe plastic deformation of the thread crest associated with crack/groove - like defect formation. (D) is the outlined area in (C) at $\times 5000$.

In stage II, the fatigue propagation plane becomes normal to the maximum tensile stress, and it is usually associated with most of the fatigue crack propagation.18, 19 It has been established that each striation formed during stage II is associated with the growth of the crack during one loading cycle, but every load cycle does not necessarily produce a striation.18 Others have shown that one striation does not necessarily correspond to one load cycle; tens to thousands of load cycles may be required to obtain one striation. 18 In this study, the observed fatigue striations on all fracture surfaces of prosthetic retaining screws were considered to result from single high - stress occlusal loads and/or multiple low stress occlusal loads. An additional observation of this study was local variations of the orientation of the fatigue striations as the crack advanced (Fig 4C). This indicates that the crack propagated through various microstructural features (multiple plateaus) that were at different elevations with respect to one another.18, 19 Stage III is the final stage of fatigue failure and involves final fracture resulting from a single overload. Final fracture may be brittle, ductile, or a combination of the two.18, 19 The dimple rupture observed in this study indicates a ductile type of final fatigue fracture in all specimens.

The ductile fracture was associated with equiaxed dimple formation except for two screws (16A2 and $17 \mathrm{~A} 1$ ) in which the final fracture was associated with elongated dimple formation. Equiaxed dimples are caused by tensile overload forces, and elongated dimples are caused by shear or tear overload forces. It has been suggested theoretically that the most posterior two implant screws in fixed detachable hybrid prostheses are subjected mainly to compression, while the most anterior implants are subjected mainly to tensile forces.21 This has never been proven clinically. The failure analysis in this study suggests that the most anterior prosthetic retaining screws are subjected to more occlusal overload force. This is supported from the location of the fatigue fracture and the higher thread wear on the middle three screws, observed and discussed in Part 1 of this series. Additionally, it suggests that the most anterior 
screws are not subjected solely to tensile force as previously proposed.21 The difference in dimple patterns (equiaxed and elongated) indicates that the prosthetic screws were subjected to a combination of tensile and shear/tear forces. The occlusal forces acting on the implant prosthetic screw are considered complex. In addition to the vertical forces induced by mastication, lateral forces are created by: (1) horizontal motion of the mandible during function; (2) inclination of the cusps; and (3) existence of parafunctional habits for long periods of time.21-24 Furthermore, all fatigue fractures, except for one screw, occurred in the shank area of the screws, rather than below the shank area or in the threaded part. It has been suggested that for adequately preloaded and torqued screws, the maximum stress from the cyclic tensile and transverse loading will be located on the shank area.25, 26 Therefore, the finding of fatigue fracture in the threaded area in one screw (Fig 11) indicates it was loose before fatigue crack initiation and fracture occurrence. It is not yet known why a fastener will self - loosen under cyclic loading and/or thermal cycles.25 It has been suggested that a fastener subjected to both tensile and transverse cyclic loading will have a vibratory motion along a circular path rather than a straight one. The vibration motion may loosen, tighten, or have no effect on the fastener.26 Therefore, the observation of fatigue fracture locations suggests that the fatigue cracks initiated and propagated in the middle anterior three screws first, and then the posterior screw started to self - loosen after experiencing higher cyclic occlusal loading before it fractured in the threaded area.



Figure 11 SEM micrograph for specimen 20B1 showing screw fracture at threaded area.

The finding of this study that the failure occurred only in retaining screws from SG after a short inservice time may be significant. The failure may be related to design incompatibility of the retaining screws from SG with the NB implant system. In Part 1 of this series, the observed unique design of the junction between the shank area and the head revealed by low-magnification SEM as wide and inclined with no head-shank fillet raised a significant concern because these screws had been considered compatible and interchangeable with the NB implant system. A retrospective assembly of one of the retrieved retaining screws from SG $\left(15 B_{1}\right)$ with NB implant components using a $3 \mathrm{~mm}$ gold cylinder (DCA 073-0 lot 0728A-03) and a standard abutment replica (DCB 175-0 Lot 123246) compared with a similar assembly using an NB hexed retaining screw and a standard abutment revealed an unexpected finding 
(Fig 12). The junction area between the head and shank of the retaining screw from SG formed a "point contact" with the gold cylinder. Such a point contact will lead to rapid and total relaxation. As the compression from the tightening torque increases, it will concentrate at a very small area, creating permanent (plastic) deformation and subsequent screw loosening. This problem can be exaggerated if a screw has lower hardness and higher preload. As mentioned in Part 3 of this series, SG screws had the highest preload and the lowest hardness. This observation might explain why fatigue failure occurred only in retaining screws from SG in Groups 16, 17, and 20 after a short period of in-service time. The manufacturer might argue that the retaining screw was not assembled with the SG implant system. The NB implant components were used based on claims of interchangeability and compatibility with the NB implant system.

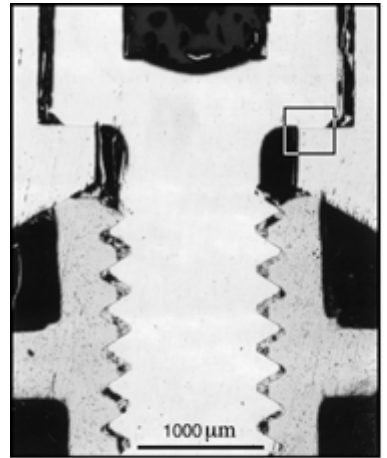

A

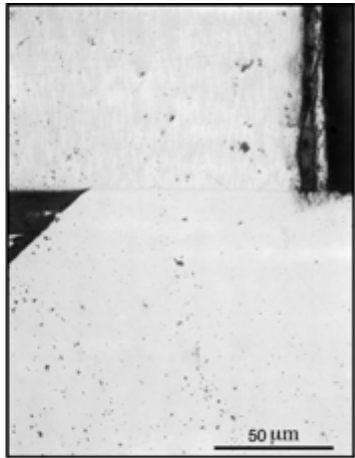

B

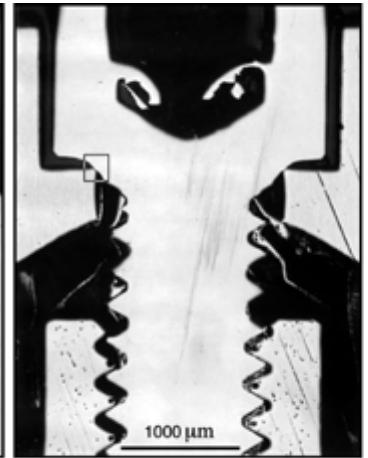

C

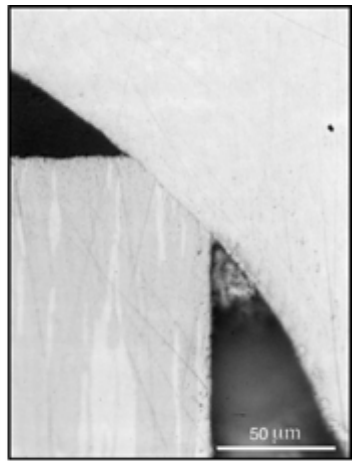

D

Figure 12 Light micrograph of assembled implant complex illustrating the assembly difference between the gold alloy retaining screws from NB and SG. NB is shown in (A) and (B), while SG is shown in (C) and (D). The outlined two areas in (A) and (C) at $\times 25$ are shown in (B) and (D) at $\times 500$. Compared to (B), the assembly in (D) formed a point contact area with the gold cylinder, which gradually will yield and deform plastically under torque preload and functional bite forces.

\section{Clinical significance}

The findings of this study and those presented in Part 1 of this series demonstrate that retaining screws from the same manufacturer and/or different manufacturers have different geometrical designs. Catastrophic failure and fatigue fracture of prosthetic retaining screws from SG may be related to design incompatibility when used with the NB gold cylinder designed for flat-headed screws. These findings support previous concerns raised by consensus of the "JOMI Current Issues Forum" in 199311 and a study in 199526 regarding interchangeable implant hardware. These emphasized that "to provide scientific proof regarding long-term survival of interchanging implant hardware between different implant system components, there is a need for long-term clinical trials." Additionally, this study reinforces previous concerns regarding the lack of written specifications for prosthetic implant components.26 Therefore, based on the findings of this study, avoiding interchanging implant components between different implant systems is highly recommended until an accurate written specification regarding geometrical design, alloy composition, and mechanical properties of implant components becomes available. This may be the only way to ensure long-term clinical performance of the prostheses. Additionally, maintaining retaining screws within their own implant system facilitates the most accurate information and best service from the manufacturer when problems arise. 


\section{Conclusions}

1) The fracture of prosthetic retaining screws in fixed detachable hybrid prostheses observed in this study suggests that failure of these types of screws occurs mainly by fatigue and involves mostly the middle anterior three screws (the screws farthest from the fulcrum).

2) Fatigue cracks can grow in more than one prosthetic retaining screw, leading to catastrophic fracture before the patient or clinician determines that any problem exists. Annual evaluation of retaining screws using stereo - light microscopy (as a suggested maintenance protocol in Part 1 of this series) may allow early detection of fatigue cracks before catastrophic failure occurs.

3) When possible, clinicians should avoid interchanging prosthetic implant components between different implant systems.

\section{Acknowledgments}

The authors thank Dr. Charles Goodacre for his valuable input during the writing of this manuscript. The authors also thank Jim Brozek for his assistance in formatting the photographs and illustrations.

\section{References}

1 Adell R, Erickson B, Lekholm U, et al: Long - term follow - up of osseointegrated implants in the treatment of totally edentulous jaws. Int J Oral Maxillofac Implants 1990;5:347-359

2 Rangert B, Krogh PH, Langer BM, et al: Bending overload and implant fracture: a retrospective clinical analysis. Int J Oral Maxillofac Implants 1995;10:326-334

3 Kallus T, Bessing C: Loose gold screws frequently occur in full - arch fixed prostheses supported by osseointegrated implants. Int J Oral Maxillofac Implants 1994;9:169-178

4 Zarb GA, Schmitt A: The longitudinal clinical effectiveness of osseointegrated dental implants: the Toronto study. Part III: problems and complications encountered. J Prosthet Dent 1990;64:185194

5 Rangert B, Jemt T, Joreous L: Forces and moments on Branemark implants. Int J Oral Maxillofac Implants 1989;4:241-247

6 Jemt T: Failure and complications in 391 consecutively inserted fixed prostheses supported by Branemark implants in edentulous jaws. A study of treatment from the time of prosthesis placement to the first annual checkup. Int J Oral Maxillofac Implants 1991;6:270-276

7 Naert I: A study of 589 consecutive implants supporting complete fixed prostheses. Part II: prosthetic aspects. J Prosthet Dent 1992;68:949-956

8 Wie H: Registration of localization, occlusion and occluding materials for failing screw joints in the Branemark implant system. Clin Oral Implants Res 1995;6:47-53

9 Goodacre CJ, Kan JY, Rungcharassaeng K: Clinical complications of osseointegrated implants. J Prosthet Dent 1999;81:537-552

10 McGlumphy EA, Robinson DM, Mendel DA: Implant superstructures: a comparison of ultimate failure force. Int J Oral Maxillofac Implants 1992;7:35-39

11 Taylor TD: Prosthodontic problems and limitations associated with osseointegration. J Prosthet Dent 1998; 79:74-78 
12 Sakaguchi RL, Sun T, Haack JE: External strain distribution on implant prosthetic components. J Dent Res 1994;73:232. Abstract 1045

13 Khraisat A, Stegaroiu R, Nomura S, et al: Fatigue resistance of two implant/abutment joint designs. J Prosthet Dent 2002;88:604-610

14 Gratton DG, Aquilino SA, Stanford CM: Micromotion and dynamic fatigue properties of the dental implant - abutment interface. J Prosthet Dent 2001;85:47-52

15 Lee J, Kim Y, Kim C, et al: Wave analysis of implant screw loosening using an air cylindrical cyclic loading device. J Prosthet Dent 2002;88:402-408

16 Hoyer SA, Stanford CM, Buranadham S, et al: Dynamic fatigue properties of the dental implant abutment interface joint opening in wide - diameter versus standard - diameter hex - type implants. J Prosthet Dent 2001;85:599-607

17 Cibirka RM, Nelson SK, Lang B, et al: Examination of the implant - abutment interface after fatigue testing. J Prosthet Dent 2001;85:268-275

18 Failure analysis and prevention. ASM Handbook, volume 11, 4th printing, 1992

19 Brooks C, Choudhury A: Metallurgical Failure Analysis. Columbus , OH , McGraw Hill, 1993

20 Bickford J, Nassar S: Handbook of Bolts and Bolted Joints. New York , NY , Marcel Dekker, 1998

21 Rangert B, Gunne J, Glantz PO, et al: Vertical load distribution on a three - unit prosthesis supported by a natural tooth and single Branemark implant. Clin Oral Implants Res 1995;6:40-46

22 Brunski J, Puleo D, Nanci A: Biomaterials and biomechanics of oral and maxillofacial implants: current status and future developments. Int J Oral Maxillofac Implants 2000;15:15-38

23 Falk H, Laurell L, Lundgren D: Occlusal force pattern in dentition with mandibular implant supported fixed cantilever prostheses occluded with complete dentures. Int J Oral Maxillofac Implants 1989;4:55-61

24 Lundgren $D$, Falk $\mathrm{H}$, Laurell L: The influence of number and distribution of occlusal cantilever contacts on closing and chewing forces in dentitions with implant - supported fixed prostheses occluding with complete dentures. Int J Oral Maxillofac Implants 1989;4:277=283

25 Bickford J: An Introduction to the Design and Behavior of Bolted Joints (ed 3). New York, NY, Marcel Dekker, 1995

26 Jaarda M, Razzoog M, Gratton D: Ultimate tensile strength of five interchangeable prosthetic retaining screws. Implant Dent 1996;5:16-19 